accumulation, was reported in the British MrDical Jouriat of April 10th; a similar case has since come under my own care, a brief report of which may also prove of interest to some of the readers of the JOURNAL.

My patient, a married lady, is also about 50 years of age. She has always been healthy, has had a family, and there is no trace of here. ditary tendency to mental disease. The duration of mental unsound. ness, when she came under my care, was said to be about three weeks. Its cause was stated to be anxiety in family matters. The mental symptoms had been great melancholy and depression; determined opposition when asked to do any ordinary or rational thing; obstinate refusal of all food; constant restlessness ; tossing her hair about and tearing it ; walking about in her night-clothes; violently refusing to be dressed. She was so violent that she could not be kept in any one position for a moment. She was absolutely incoherent in conversation; had not slept for many nights; and could not be controlled.

On examination, she was found to be violent and resistive; her hair was in greatdisorder; she was constantly restless, moved continuously, swaying backwards and forwards from one foot on to the other. Her breath was offensive, and had the odour peculiar to abstinence from food. She was profoundly taciturn, incomprehensive, lost, and bewildered; and absolutely refused all food, nourishment, or even water. It was found necessary, in order to sunport her strength, at once to administer liquid nourishment by means of the stomach-pump ; and this was, of necessity, afterwards repeated three times daily. At the end of a week, all medicines and enemata given having failed to act satisfactorily upon the bowels, and it having been ascertained that the same condition of things had been in existence three or four weeks previously, examination per rectun was made, when a dense and hardened mass of scybala was found; it was broken up, and partially removed by means of spron-handles; and this, followed by a renewed enema of several pints, thoroughly evacuated the lower bowel.

Up to this time, the mental symptoms had continued as they have already been described, notwithstanding also a very large amount of liquid nourishmentand stimulantadministered mechanically; the tongue had remained dry, coated, parched, and parchment-like; the lips and teeth were similarly coated, the former becoming dry and excoriated. But, very soon after the free evacuation of the bowels, all the worst symptoms began gradually to disappear. Consciousness and comprehension returned, and attempts were made to partake of food and nourishment naturally. These favourable symptoms have steadily gone on since; and now, the third week of treatment of what promised to be a formidable and prolonged attack of melancholia, with stupor, finds the patient calm, coherent, sensible, industrious-with, in short, convalescence perfectly established, and discharge from care imminent.

\section{A CASE OF RHINOSCLEROMA.}

\section{BY SIDNEY DAVIES, M.A., M.B.(Oxon.), Cairo.}

THE patient was a woman, named Sittayta $\Lambda$ hmed, aged 30 , a native of Egypt, and living in Cairo. Her occupation is cooking and selling sheeps' heads and trotters. She has been married twelve years, and had six children, four of whom have since died.

History. - She did not remember having any previous illness, with the exception of an ulcer on her left wrist. About a year before her marriage, she first noticed a small swelling in the septum nasi, which had gradually increased and extended until the time I saw her. There had wever been any discharge, and she had never noticed anything wrong in her throat.

Description. - She was first seen by me in the beginning of March, 1885 , and then presented the following appearance. She had a healthy complexion, was well nourished, and pregnant; she had ulcerations of the corneæ. The appearance of her face was striking, and rather repulsive, owing chiefly to the great breadth of the nose. The internal canthi of the eyes were two inches apart, and the breadth between the alæ nasi also two inches. The nose appeared correspondingly flattened. The nostrils were filled up by a hard resisting growth, of the same colour as the lips; this growth extended from the lower border of the nostrils half way down the lips. This part of the growth was elevated about a quarter of an inch above the skin. The nostrils were represented by two pin-holes, through which a probe could be passed to the back of the pharynx. The septum and all the nasal cartilages were much thickened. The nasal bones seemed unaffected. The soft palate and fauces were abnormal; the uvula was not visible, and the mucous membrane of the soft palate appeared pale, infiltrated, eontracted, and rigid. On passing the finger into the pharynx, a growth could be felt filling up the posterior nares, similar, but not so dense, as that in front. The postcervical glands were enlarged. There was a moderately enlarged thyroid body. The legs were normal.

Treatment. - The patient was treated for three weeks with iodide of potassium in large doses, and liquor hydrarygri perchloridi. No improve. ment took place, and she was anxious for an operation. Accordingly, on April 3rd, in the presence, and with the assistance of Drs. Vernoni, Sandwith, and Richer, I cut away the chief part of the growth in the left nostril, and then applied the benzine cantery, burning a passage through to the pharynx. The wound healed in a few days, and the patient found relief and comfort from the enlarged meatus. At her request, I operated in a similar way on the right nostril on April 14th, making a passage rather larger than on the first occasion. I saw her again in the middle of October. Her appearance was somewhat improved, owing to the partial destruction of the growth on her upper lip ; but what she considered of higher importance, her facility of respiration and speech continued very greatly enhanced. The nasal meatus on each side had partially filled up, but to a smaller extent than I expected. They would admit a fair sized quill.

Microscopic Examination. - Part of the growth removed in the operation was kindly examined for me by Dr. Brugich, at the Khedivial Laboratory, by sections, staining, and cultivations; no bacteria were found. Sections showed a small celled infiltration of the papillæ and chorion of the skin, similar to the appearances described by Kaposi.

REMARKs. - Rhinoscleroma was first described, in 1870, by Hebra and Kaposi, and is still so rare a disease, that no excuse is needed for reporting a new case. When I first saw this case, I regarded it as an unusual manifestation of syphilis, the woman having a doubtful syphilitic history. While the patient was under treatment, I noticed the account in the British Mledical Journal for March 7th, 1885, of the case described by Drs. Payne and Semon, by means of which I at once identified the present case as rhinoscleroma.

As far as I am aware, this is the first case observed in Egypt. It was shown by me to many of the leading members of the profession in Cairo, including Dr. Sonsino. None had seen a similar case before, excepting Dr. Urldt, who had seen one in Germany, and recognised the similarity of my case to the one he had seen. My case agrees in nearly all particulars with that of Drs. Payne and Semon. Notes of epidermic cells were not observed, however.

Dr. Morell Mackenzie has given a short summary of all that is known respecting this disease in his Diseases of the Throat and Nose. He remarks: "Of a total of about forty cases hitherto observed, all but three were met with in Vienna or its neighbourhood. Two of these occurred in Italy and one in France, but $I$ am not aware of a single instance in which the disease has been noticed in any other country."

\section{A CASE OF THYROIDECTOMY.}

BY J. P. BRAMWELL, M.D., L.R.C.S., Visiting Surgeon to the Perth Infirmary.

Twelve months ago, a young farmer, in the neighbourhood of Perth, consulted me regarding a swelling in his neck, which I found to be a goître. It was not of large proportions, but was situated directly over the trachea. There were no urgent symptoms, but, as I had shortly before seen a goîterous patient die of sudden asphyxia, in whom the growth was very large, I deemed it safest to ask my patient to have his thyroid gland removed before it became larger. To this proposal he consented, and was placed under my care in the Perth Infirmary. A free incision was made in the mesial line, and the whole gland dissected out. The hæmorrhage was very profuse and alarming, but was at last effectually arrested.

We had not, however, done with our troubles.; High fever ensued, followed by an attack of erysipelas all over the anterior aspect of tho neck, and then a free suppuration of the wound. All this, however, subsided shortly, and the wound closed apace. In two or three weeks afterwards, he returned home in good health.

REMARKS. - I have watehed this case, from time to time, during all this period, by inquiring of his relatives, and by personal interviews with the patient himself; but there never has boen any apprecisble degeneration, either mental or physical-in fine, no cachexia strumipriva. With such a fact before us, it is tolerably clear that we have not as yet discovered the true function of the thyroid, and that the whole question is, as yet, sub judice. The thyroid has boen credited with too many functions to be all correct; for example, a destroyer of ptomaines, a metaboliser of muceine, a ragulator of the corebral circulation; and a medical friend informs me that, after an operation 